\section{Abstract}

In 2009, 4 major bushfires destroyed vast areas of Gippsland in eastern Victoria including the areas around Delburn, Bunyip, Churchill and Wilsons Promontory. These are collectively known as the 2009 Gippsland bushfires. Research was conducted to investigate the psychosocial recovery of young adults in these areas. Twenty young adults participated in the study and, while these young adults are not an homogenous group, commonalities were identified across their stories. Asked what would have helped their recovery, the participants all said that acknowledgment of their personal and age-specific needs was the single most important factor that enabled or impeded recovery. This paper describes some of their stories. The paper looks at how participants viewed acknowledgment and the effects of its absence on their psychosocial recovery and how they felt unacknowledged in local recovery supports. The paper reports on the findings of this research and suggests an approach for management and longer-term recovery support that is inclusive of the specific needs of young adults.

BASED ON A PAPER PRESENTED AT THE AUSTRALIA \& NEW ZEALAND DISASTER \& EMERGENCY MANAGEMENT CONFERENCE 2020.

\title{
The role of
}

\section{acknowledgment in the psychosocial recovery of young adults in disaster events}

Peer Reviewed

\section{Dr Rouve Jan Forbes ${ }^{1}$ \\ Dr Julie Willems ${ }^{1}$}

Dr Margaret Simmons ${ }^{1}$

1 Monash Rural Health, Monash University,

Churchill, Victoria.

\section{SUBMITTED \\ 9 November 2020}

\section{ACCEPTED}

22 December 2020

DOI

www.doi.org/10.47389/36.2.42

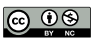

(C) 2021 by the authors. License Australian Institute for Disaster Resilience, Melbourne, Australia. This is an open access article distributed under the terms and conditions of the Creative Commons Attribution (CC BY) license (https:// creativecommons.org/ licenses/by/4.0/).

\section{Introduction}

Research conducted in 2015 and 2016 explored how young adults in rural areas were faring in their psychosocial recovery from the 2009 Gippsland bushfires. Twenty young people ${ }^{1}$ from rural and regional areas in Gippsland who selfidentified as being a young adult and affected by the 2009 Gippsland bushfires participated in the study.

At the time of the fires, weather conditions were rated as 'catastrophic' and this was reflected by one of the participants who was in her early 20s at the time, was actively involved in firefighting efforts and resided in the Gippsland bush:

We were alert and ready to go, sitting in 48-degree heat with gusting 100 kilometres per hour winds. All we could do was watch this fire grow more voluminous, moving quickly across the landscape. Later when it was deemed safe enough for us to be at the fire line, we focused on asset protection at some rural properties exposed to the flank of the still moving fire.

Tamsin

Several themes emerged from the research. A separate paper explored the use of social media and the rise of virtual communities for young adult recovery (Willems, Forbes \& Simmons 2021). This paper builds on previous research that considered the lack of acknowledgment as being a key factor influencing the post-disaster recovery of young adults (Forbes, Simmons \& Willems 2018). Further synthesis of that data collected data yielded 3 additional findings relating to acknowledgment. First, acknowledgment of personaland age-specific needs is important for the psychosocial recovery of young adults. Second, post-disaster recovery continues long after an event has passed. Finally, young adults must be included in emergency and disaster planning,

1 Names of participants have been changed and pseudonyms have been used in this paper. 
M RESEARCH

and in discussions around longer-term recovery support, such as ways to foster their physical, mental and financial health. The stories of psychosocial recovery of participants are shared to show how acknowledgment (or its lack thereof) continues to affect these young people. Their perceptions, reflections and lived experiences as presented were analysed to enable recommendations for relevant policy adjustments. These could also contribute to emergency management planning to support young adults through this and future terrible events.

\section{Young adults and disasters}

The term 'young adult' refers to a transitional stage of development between childhood and adulthood. It is therefore somewhat ambiguous with no clear characteristics to define the beginning or end point (Chudacoff 2004, Galland 2007). However, in Australia, the legal age for adulthood is 18 years. The Australian Bureau of Statistics (ABS 2013) defines 'young adult' as people aged between 18 to 34 years.

Young adults, as a specific cohort with unique and individual needs, are different from those of children and older adults. This is one of the few studies globally to have explored this research gap (Cox 2017). In relation to research on young adults and disasters, while there is a plethora of literature from researchers on recovery, research specific to youth tends to target children and young people under 18 years old, occasionally extending up to 25 years of age (Caruana 2009, Hosin 2007, McDermott 2004). The gap in research requires a focus on young adults in the 18-to-34year age range, particularly on the effects of informal and formal psychosocial post-disaster supports in their recovery (Forbes, Jones \& Reupert 2012; Hubbard 2014). In addition, as personal recovery is complex and varied and can take up to 5 years or longer following a traumatic event (AIDR 2018, Bryant et al. 2018), investigating young adult psychosocial post-disaster recovery needs to delve beyond the short-term.

Recovery is aided by acknowledgment and that being acknowledged is a protective factor for mental health and wellbeing (Maercker et al. 2009a). "'Acknowledgment' is the social appreciation of a person's unique experiences, including their social setting" (Maercker et al. 2009b). Without acknowledging a person's experiences, a negative feedback spiral can arise. In such a scenario, there could be disengagement from recovery processes, a lack of social support-seeking and the potential for disillusionment and heightened distress. This negative spiral reinforces the original lack of acknowledgment that people experience (AIDR 2018; Forbes, Jones \& Reupert 2012; Maercker et al. 2009).

Communicating personal recovery needs is vital and can be achieved through the telling of stories. Stories help people make sense of their experiences and the experiences of others (Frank 2014). Having the opportunity to tell one's story-of being heard and understood-is a crucial step to acknowledgment and recovery (Barker 2007, Gordon 2016). It is important that young adults are acknowledged and this can be done by providing them space to express themselves and say what they consider is important in their recovery. These accounts are important contributions to recovery and the planning of response and recovery support services.

\section{Methodology}

To understand young adults' specific recovery needs it is important to consider their interactions with their families and peers, their communities and the various emergency services personnel and support providers. Social constructionism was employed to interrogate how bushfire recovery frameworks and social contexts affected young adults. Social constructionism are explanations that acknowledge people's stories and lived experiences (Denzin \& Lincoln 2011). Storytelling is an effective qualitative methodology for this research because it aims for richness and depth, which are both key elements in this study. For the purposes of this study, these explanations are examined in terms of psychosocial recovery; a term that encompasses the many social and behavioural factors that influence the health and wellbeing of young adults (Hawe 2009).

At the time of the 2009 Gippsland bushfires, the study participants ranged in age from 18 to 26 years, falling at the lower end of the ABS (2013) young-adult range of 18 to 34 years. Twenty young adults who were personally affected by the bushfires voluntarily participated in the study that was conducted in 2016.

Data was collected via a survey featuring mainly qualitative questions with the addition of quantitative demographic questions to gather details of age, gender, occupation and location during and after the bushfires. The survey was offered online and in paper format depending on participant preference. The survey was supported by an in-depth recorded telephone interview. While an interview guide was used for the qualitative interviews, participant' responses instigated further questions in an iterative process. Qualitative comments from the surveys and telephone interviews were transcribed verbatim with selected quotes from participants used to illustrate the stories uncovered. Participants were given a pseudonym to protect their identity. Ages were bracketed into broad groups (e.g. early or mid-20s). The data was analysed using a thematic analysis approach as outlined by the Braun \& Clarke (2013) phased method of contextualising young adults' accounts in order to better understand their experiences.

Ethics approval for the project was granted in 2015 (CF14/35552014001877) from the Monash University Human Research Ethics Committee.

\section{Results}

The bushfire experiences and recovery journeys of these young adults, as explored through the interviews and surveys, were complex and diverse. Collectively, participants experienced various hardships and challenges. Their losses were both tangible and psychological. While most participants were not homeowners, some did lose their home or their family's home. Their losses also included the loss of friends, people in their community, pets, livestock, employment and livelihoods, personal belongings and memorabilia. Their life trajectory and sense of safety and security was disrupted. The young adults also suffered the damage to the natural environment and related fauna and flora in the region. 
The young adults were also commonly in the process of moving to, or from, the area because of life transitions such as relationships, jobs or education. Most participants reported that this mobility excluded them from 'place-based' recovery supports and that once they had left home, school and the area, they often felt lost in a void. While participants' losses were disparate, it was identified that they all had some unique needs for their age and demographic group. According to Hawe (2009), young adults may not have developed the skills required to recognise and manage difficult emotions and they thus have particular requirements related to their identity and their place in the world. As 'Jemma' in her early 20 s and working in healthcare at the time of the bushfires wrote:

I think that everyone grows emotionally between the age of 20 and 30, and that you're still sort of trying to define who you are as an adult and where your place is.

Jemma

In terms of identity and recovery, some participants considered they were well along the road in recovery, while others indicated they were still processing and managing emotional, physical and material consequences of the bushfires some 6 or 7 years later. While not a homogenous group, all participants reported that acknowledgment, particularly acknowledgment of their personal and age-specific needs, was pivotal to their recovery. One participant, 'Finn', a student in his early 20s at the time of the bushfires provided an insightful explanation of recovery as being both long-term and context-dependent:

Recovery seems to be a two-fold issue. First, it's about getting people to a state where they can feel a sense of both normality and value in their region and communities. Support programs seem useful here in assisting families and communities to help one another along. Second, recovery means acknowledging that Gippsland is located in an area that is likely to become fire prone during dry years and to have the appropriate mechanisms put in place to mitigate or prevent future risky events.

\section{Finn}

For Finn, recovery was perceived as solution oriented. It involves people being valued and acknowledged for their unique needs. As a concept, acknowledgment by peers, community members and authorities include a person's social setting, social recognition and acceptance (Maercker \& Müller 2004).

When participants were asked what acknowledgment meant to them, they described concepts involving recognition, acceptance and consideration of personal trauma by family, friends,

communities and support workers. Further, participants wanted to be accepted as deserving and legitimate members of the fireaffected community in which they lived. 'Felicity', a business owner and operator in her mid-20s at the time of the bushfires wrote:

Acknowledgment? ... I suppose it just means that people realise that you've been through a traumatic experience ... it's not just the parents, it's the whole family ... you know, it's everybody.

Felicity
However, many participants noted that they did not receive acknowledgment, particularly from external support providers. 'Harriet', a volunteer wildlife rescuer in her late teens at the time of the bushfires explained:

... being offered things ... is just a form of acknowledgment, but ... it's ... one thing to be acknowledged by a close friend and it's another thing to be acknowledged by perhaps an organisation or someone who's that sort of one step removed. It's ... like if they can see, it becomes ... real.

Harriet

Some participants were ineligible for post-disaster support that might have acknowledged and supported their unique needs. As 'Tilly', a student in her late teens at the time of the bushfires said, 'I really was not part of the community recovery events. Being eligible for support would have helped my recovery'.

When some support and post-disaster activities were provided to young adults, they were often inappropriate to the age group. 'Ryan', a student in his late teens at the time of the bushfires explained that post-disaster supports were aimed at younger people or were not suitable for young adults:

[t]here was paintballing and ... and skydiving, but I wasn't fussed. I had [had] enough excitement. I think I got a couple of invitations but not really for young adults, more like ... for those a bit younger.

Ryan

Along with other participants, 'Laurel', a musician looking for work and aged in her mid-20s at the time of the bushfires said she had received little acknowledgment of her particular experience, thus preferring not to share her story widely:

... [and] not often in great depth. People don't understand, and I don't like to waste words. This far down the track I prefer to move on rather than talk about it. The time for talking has passed for me.

Laurel

Laurel's reflections indicate that recovery can take a long time and that recovery supports should extend beyond the immediate aftermath. According to Gordon (2016), recovery is an ongoing process that may not necessarily have an endpoint. The notion of a recovery journey is emphasised by 'Jack', a volunteer firefighter in his early 20 s at the time of the bushfires:

I feel like it's still a process and although a lot of people have moved on as best they can it's forever going to be a part of their lives. You can't forget that kind of thing, however big or small the impact is, there still will be an impact.

Jack

Many participants talked in longitudinal terms regarding their recovery using temporal language such as 'for a long time'. 'Mary', a student in her late teens at the time of the bushfires recounts, 'I thought I had to put on a bit of a face that I was alright, 
" RESEARCH

and that went on for a very long time ... I thought at the time I was doing ok ... but I was struggling'.

The perception of a long-term recovery struggle is similar to Laurel's view, as she explains, she felt:

...very lost for a long time, felt I didn't fit anywhere in the world any more as my 'safe place' had been taken away from me, and my friends (none of whom were impacted) had no understanding of what I had been through, and continued to go through for a very long time.

Laurel

'Molly', in her early 20s was a volunteer at a relief centre following the bushfires reflected on how long and lasting the personal recovery process may be, even with recovery supports:

Since the fires I have gained more of an awareness of how long the recovery process can take. It's quite surreal in terms of the lasting impact of such great destruction, and how adjustments can take quite a while, despite systems of support from governments or insurance agencies.

\section{Molly}

Molly's reflections are significant because disaster recovery is often measured in terms of material rebuilding but in many cases, adjustments and recovery allude to regaining a sense of emotional safety over time. Tilly concurs:

Now it is quite good, for a long time though it was not. Now I feel that I am in a solid emotional state currently. However, for the first few years following the fires I experienced a 'rollercoaster' of emotions.

\section{Tilly}

It is clear from participants' comments that recovery is a dynamic and at times prolonged process that may take many years. It is vital therefore, that 'time' is considered an integral aspect of recovery support mechanisms. In terms of support systems and emergency policies, the next section of the article's results will highlight the importance of including young adults in this wider community recovery discussion.

Young adults must be included and acknowledged in the broad discussions around recovery support mechanisms and emergency relief systems even though it appears that in many instances following the 2009 Gippsland Bushfires, they were not. This exclusion is unfortunate, because young adults have many interesting and informed ideas for how the distribution and reach of support could be improved for this cohort; some of which will be outlined herein. However, it must be noted that many of the research participants regard their exclusion from such supports as benign rather than deliberate. For example, Laurel speculated on the chaotic situation of the recovery processes and the disruption to normal social structures as a result of the bushfires, stating that, '[w]ithin communities that have suffered disaster it is understandable that young adults' needs were overlooked because everything was "upside down"'.
'James', aged in his early 20s and working in the local power industry at the time of bushfires considers that young adults' voices are often overpowered by the needs of older members in the community, remarking that 'older people ran the community recovery meetings and so they planned for their own needs'. 'Oscar', a student in his early 20s at the time of the bushfires said, '[y]oung adults definitely missed when it came to funding, psychological support ... case management, etc. It felt like there was nothing available'. 'Harriet' concurred saying, '[t]here could be more supports that are specific to our age group. I know a lot of young people missed out on support'.

'Beth', a student in her late teens at the time of the bushfires reflected that young adults 'were outnumbered and because there wasn't a large amount of them having a voice and creating attention ... that was a reason they were overlooked'. Beth's observation accords with the actual demographics in small rural communities, where young adults make up less than 14 per cent of the population (ABS 2013). Nevertheless, there is great merit in including the voices of young adults because of the contributions they made both during and after the disaster along with their potential contributions in future disaster policy, knowledge and management. It should be noted that young adults were also often in the process of moving to or from the area because of life transitions such as relationships, jobs or education, which may have invalidated them from 'place-based' recovery supports.

Further, the research identified young adults missing out on support alongside self and community perceptions of them being able to quickly recover or 'get over' their experiences. Tilly summarised this sentiment: '[m]any were left out. People thought that they were young and would get over it fast'. There are many cultural narratives and stereotypes around young adults that position them as a separate and marginalised group that is somehow undeveloped and needs to be managed (Allen 2008; Raby 2007). Yet, there is also a paradox in the notion of young adults needing protection but also being resilient and able to quickly recover from disaster, as Beth notes:

I suppose I'm young and I have that opportunity to build up again, whereas I can imagine for a middle aged or older person people they might have perceived their loss as more of a sort of overwhelming loss... Whereas I think people my age sort of realise there is a future, like you've got a lot of time to build up again and to change things.

Beth

In addition to the importance of hearing their stories, participants indicated that the telling of their story was a powerful aspect of their recovery. 'Karen', a mental health worker in her early 20 s at the time of the bushfires observed that the interview process, '[o]ffered an opportunity over repeated telling to validate and understand [the] experience of the fires'. The stories of young adults support Frank's (2010) contention that telling your story can be therapeutic and cathartic. 


\section{Discussion and recommendations}

In the context of the increasing frequency and severity of extreme events in Australia, and particularly in Gippsland (one of the most bushfire-prone regions in the world (AIDR 2018)), this research provided compelling arguments for including young adult voices and acknowledging their unique needs and experiences related to recovery. The stories in this research show there is an imperative to listen to young adults and to develop appropriate ways and spaces to acknowledge and include them. According to Raby (2007, p.46), we need to understand young adults' lived experiences because they '... are experts in and remain gatekeepers of their own cultures'. Providing a space where young adults can express themselves can be empowering and may enable personal agency as experts in their own culture.

There may be multiple reasons for the exclusion of young adult voices in recovery support mechanisms apart from fewer numbers and reduced mobility. There are power imbalances between adults and young people, where adults generally have access to greater resources and the decision-making processes (Raby 2007). Young people lack the political and financial advantages and access of older people and there are constantly shifting platforms between their 'dependence and independence' that further serves to marginalise them (Raby 2007, p.47). Raby (2007) also explains that young adults may have different social and communication skills that inhibit their ability to actively participate in societal discourses, particularly during and after traumatic events. It is essential to view young adults as 'social agents who are active meaning-makers in their own lives...' (Allen 2008, p.565) and their inclusion in recovery mechanisms is important.

To effect young adult inclusion in recovery supports, several recommendations emerge from this research. Local, state and federal government policy makers and planners, service providers, community stakeholders and social researchers must listen to and include input from young adults and their experiences. Participants in this research were anxious to express themselves to an audience. Thus, providing avenues to facilitate this could be pursued, including through social media, prose and poetry, music and the creation of story books. Those involved in emergency management planning could develop ways of providing access to both short- and longer-term recovery supports for young adults. Consideration of placing acknowledgment as an activity for recovery can address current dilemmas and validate the losses and personal situations of young adults.

This research supports the argument that young adults (18 to 34) be recognised as a significant and separate age cohort and have access to recovery services specific to their needs and appropriately funded. There is an urgent need to develop policy and service provision guidelines that acknowledge young adults as a distinct demographic. There is also a need for activities that are appropriate to all ages and abilities but particularly activities targeted towards connecting with young adults on their terms (Hawe 2009). It is recommended that young adults be invited to participate on community recovery advisory committees as equal members and have access to advocacy and mentorship. Further research is required to evaluate progress and to increase young adult participation to continually improve emergency management policies and support systems.

\section{Research limitations}

This research looked only at the experiences of young adults in general and did not analyse experiences based on gender, sexuality or ethnicity. Other marginalised groups and other age groups, including parents with young families, could be studied to provide insights into the diverse recovery experiences and requirements. Further studies might explore different communities and locations or different events.

The young adults in this research were highly protective of the efforts of their parents and the community to support them and others after the bushfires. A limitation in the study was participants' concerns that sharing information might be potentially emotionally damaging to their family and community. Participants were keen to avoid notions that their stories might appear to belittle the recovery efforts of others. While reassured to the privacy and confidentiality of the research, these concerns may have been factors in reducing participation. Those who participated despite these concerns also expressed a sense of obligation to share their stories in the hope that it would make a difference to future recovery efforts for other young adults.

Considering these limitations, this research has nevertheless explored new ground and could be replicated in a larger study into the long-term recovery of young adults.

\section{Conclusion}

This research examined the psychosocial recovery and support for a group of young adults following the 2009 Gippsland bushfires. It considered young adults as a specific cohort with unique and individual needs that are different from those of children and older adults. The study examined young adults' longer-term psychosocial recovery within a decade of the 2009 Gippsland bushfires and is an important part of the picture beyond that event.

The work has implications for both policy and planning. Acknowledgment of personal and age-specific needs is important to assisting in the psychosocial recovery of young adults. The integration of their stories highlights how acknowledgment (or the lack thereof) influences recovery. Post-disaster recovery continues long after an event has passed. According to Spencer and Doull (2015, p.901), '...a better understanding of young people's lived experiences can reveal possibilities for young people's agency to emerge'. This research encourages the inclusion of young adults in emergency management activities, planning and in longer-term recovery supports due to their invaluable and age-specific insights.

\section{References}

Allen L 2008, Young people's 'agency' in sexuality research using visual methods, Journal of Youth Studies, vol. 11, no. 6, pp.565-577.

Australian Institute for Disaster Resilience (AIDR) 2018, Australian Disaster Resilience Handbook Collection: Community Recovery - Handbook 2 (3rd ed). At: https://knowledge.aidr.org.au/ media/5634/community-recovery-handbook.pdf. 
Australian Bureau of Statistics (ABS) 2013, 4102.0 - Australian social trends: Young adults then and now. At: www.abs.gov.au/AUSSTATS/ abs@.nsf/Lookup/4102.0Main+Features40April+2013.

Barker G 2007, Adolescents, social support, and help-seeking behaviour: An international literature review and programme consultation and recommendation for action. Geneva: World Health Organization Press.

Bishoff C 2008, With new eyes to see, in ME Moore \& AM Wright (Eds.), Children, youth and Spirituality in a troubling world, pp.168-182, Missouri: Chalice Press.

Bryant RA, Gibbs L, Gallagher HC, Pattison P, Lusher D, Macdougall C, Harms L, Block K, Sinnott V, Ireton G, Richardson J \& Forbes D 2018, Longitudinal study of changing psychological outcomes following the Victorian Black Saturday bushfires. Australian and New Zealand Journal of Psychiatry, vol. 52, no. 6, pp.542-551. doi: 10.1177/0004867417714337

Caruana C 2009, Life in the aftermath, Family Relationships Quarterly, vol. 14, pp.3-7.

Chudacoff H 2004, Adolescence and Youth, in S Fass (Ed.), Encyclopedia of Children and Childhood in History and Society (vol. A-E), pp.15-20, New York: Thomson Gale.

Cox R, Scannell L, Heykoop C, Tobin-Gurley J \& Peek L 2017, Understanding youth disaster recovery: The vital role of people, places, and activities, International Journal of Disaster Risk Reduction, vol. 22 (June), pp.249-256. doi:10.1016/j. ijdrr.2017.03.011

Denzin NK \& Lincoln YS (Eds.) 2011, The Sage handbook of qualitative research (4th ed.). Thousand Oaks, CA: Sage.

Forbes R, Simmons M \& Willems J 2018, Beyond the 2009 Gippsland bushfires: Acknowledgment and young rural adults' recovery, Australian Journal of Emergency Management, vol. 33, no. 1, pp.32-37.

Forbes R, Jones R \& Reupert A 2012, In the wake of the 2009 Gippsland fires: young adults' perceptions of post-disaster social supports, Australian Journal of Rural Health, vol. 20, no. 3, pp.119-125. doi:10.1111/j.1440-1584.2012.01271.x

Frank AW 2014, Narrative Ethics as Dialogical Story-Telling, Hastings Center Report, vol. 44(s1), S16-S20. doi:10.1002/hast.263

Galland O 2007, Boundless youth: Studies in the transition to adulthood. Oxford, UK: Bardwell Press.

Gordon R 2016, Long-term impact of disaster experience 2009. At: www. bef.net.au/study.htm.

Hawe P 2009, Community recovery after February 2009 Victorian Bushfires: A Rapid Review. Melbourne: Sax Institute for the Victorian Government Department of Health.

Hosin AA 2007, Responses to traumatized children. Basingstoke: Palgrave Macmillan.

Hubbard B 2014, Report to the Victorian Government of the 2009 Bushfire-affected Communities-Five Year Consultation. Melbourne: Victorian Government. At: www.rdv.vic.gov.au/_data/ assets/pdf_file/0005/1684625/Victorian-Bushfire-5-Year-Report297×210mm-Online.pdf.
Maercker A, Mohiyeddini C, Müller M, Xie W, Yang Z, Wang J \& Müller J 2009a, Traditional versus modern values, self-perceived Interpersonal factors, and post-traumatic stress in Chinese and German crime victims, Psychology Psychotherapy, vol. 82, no. 2, pp.219-232.

Maercker A, Povilonyte M, Lianova R \& PöhImann K 2009b, Is acknowledgment of trauma a protective factor? The sample case of refugees from Chechnya, European Psychologist, vol. 14, no. 3, pp.249-254

Maercker A \& Müller J 2004, Social acknowledgement as a victim or survivor, Journal of Traumatic Stress, vol. 17, pp.345-351.

McDermott B 2004, Child and youth emotional trauma: An explanatory model of adverse outcomes, Journal of Psychiatry, vol. 11, no. 2, pp.269-279.

Raby R 2007, Across a great gulf? Conducting research with adolescents, in AL Best (Ed.), Representing youth: methodological issues in critical youth studies, pp.39-59, New York: New York University Press. ProQuest Ebook Central.

Spencer G \& M Doull 2015, Examining concepts of power and agency in research with young people, Journal of Youth Studies, vol. 18, no. 7, pp.900-913.

Willems J, Forbes RJ \& Simmons M 2021, Beyond place-based: the role of virtual communities via social media in young adult recovery, Australian Journal of Emergency Management, vol. 36, no. 2, pp.42-47.

\section{About the authors}

Dr Rouve Jan Forbes has a background in community health nursing. She received a 'Certificate of Appreciation' from the Australian and Victorian governments for her significant commitment and contribution to the recovery and rebuilding efforts following the 2009 Gippsland bushfires. She has recently completed her PhD at Monash University.

Dr Julie Willems is a researcher at Monash University and holds qualifications in nursing, education and the humanities. She received an auDA Foundation research grant in 2011 for the i-Survive Project that explored the use of 'back channel' communications via mobile social media during emergencies and disasters.

Dr Margaret Simmons is a researcher at Monash University. She teaches a social perspective on health in the graduate medical program and was the recipient of the Vice-Chancellor's Award for Excellence in Inclusion and Diversity in 2020. 